Article

\title{
The Effect of Copper Addition on the Activity and Stability of Iron-Based $\mathrm{CO}_{2}$ Hydrogenation Catalysts
}

\author{
Matthew J. Bradley ${ }^{1}$, Ramagopal Ananth ${ }^{2}$, Heather D. Willauer ${ }^{3, *}$, Jeffrey W. Baldwin ${ }^{4}$, \\ Dennis R. Hardy ${ }^{5}$ and Frederick W. Williams ${ }^{2}$ \\ 1 ASEE Postdoctoral Research Associate, Naval Research Laboratory, Materials Science and Technology \\ Division, Washington, DC 20375, USA; matthew.bradley.ctr@nrl.navy.mil \\ 2 Naval Research Laboratory, Chemistry Division, Washington, DC 20375, USA; \\ ramagopal.ananth@nrl.navy.mil (R.A.); fredsshadwell@gmail.com (F.W.W.) \\ 3 Naval Research Laboratory, Materials Science and Technology Division, Washington, DC 20375, USA \\ 4 Naval Research Laboratory, Acoustics Division, Washington, DC 20375, USA; jeff.baldwin@nrl.navy.mil \\ 5 NOVA Research Inc., 1900 Elkin Street, Alexandria, VA 22308, USA; kashardy@gmail.com \\ * Correspondence: heather.willauer@nrl.navy.mil; Tel.: +1-202-767-2673
}

Received: 4 August 2017; Accepted: 13 September 2017; Published: 20 September 2017

\begin{abstract}
Iron-based $\mathrm{CO}_{2}$ catalysts have shown promise as a viable route to the production of olefins from $\mathrm{CO}_{2}$ and $\mathrm{H}_{2}$ gas. However, these catalysts can suffer from low conversion and high methane selectivity, as well as being particularly vulnerable to water produced during the reaction. In an effort to improve both the activity and durability of iron-based catalysts on an alumina support, copper $(10-30 \%)$ has been added to the catalyst matrix. In this paper, the effects of copper addition on the catalyst activity and morphology are examined. The addition of $10 \%$ copper significantly increases the $\mathrm{CO}_{2}$ conversion, and decreases methane and carbon monoxide selectivity, without significantly altering the crystallinity and structure of the catalyst itself. The $\mathrm{FeCu} / \mathrm{K}$ catalysts form an inverse spinel crystal phase that is independent of copper content and a metallic phase that increases in abundance with copper loading $(>10 \% \mathrm{Cu}$ ). At higher loadings, copper separates from the iron oxide phase and produces metallic copper as shown by SEM-EDS. An addition of copper appears to increase the rate of the Fischer-Tropsch reaction step, as shown by modeling of the chemical kinetics and the inter- and intra-particle transport of mass and energy.
\end{abstract}

Keywords: $\mathrm{CO}_{2}$ conversion; selectivity; activity; modelling; iron-based; copper

\section{Introduction}

The Department of Defense (DOD) is the single largest buyer and consumer of jet fuel in the world [1,2]. Currently, it is estimated that DOD purchases almost 3 billion gallons of jet fuel per year. Due to the instability in fuel prices and a foreseeable reduction in fossil fuel resources, the U.S. Navy has an interest in maintaining U.S. energy security long term by investing in new sources of fuel that are more environmentally friendly [3]. Generating jet fuel from environmental sources of carbon dioxide $\left(\mathrm{CO}_{2}\right)$ and hydrogen $\left(\mathrm{H}_{2}\right)$ at the point of use could lead to strategic advantages and potential long term cost savings [4]. A key part in successfully synthesizing jet fuel from these resources involves the development of stable and highly selective $\mathrm{CO}_{2}$ hydrogenation catalysts for thermochemical processes.

The abundance of $\mathrm{CO}_{2}$ in the atmosphere and its documented impact on climate change have led to a rapidly growing research effort associated with using it as a carbon source [4-6]. Carbon and hydrogen are the principle building blocks needed to synthesize hydrocarbons or alcohols [7] to be used as chemicals and/or fuel. However, thermochemical methods for synthesizing fuel from $\mathrm{CO}_{2}$ require overcoming a large energy barrier and the energetically costly electrolysis process used to produce $\mathrm{H}_{2}$ [6]. A review by Porosoff et al. [8] addresses the need to develop catalysts that increase the 
efficiency of hydrocarbon production as well as decrease undesirable side products, such as methane and carbon monoxide, from the product stream.

Due to a combination of factors including cost, abundance, and activity, iron-based catalysts have been identified as candidates for industrial $\mathrm{CO}_{2}$ hydrogenation. However, one challenge with iron-based $\mathrm{CO}_{2}$ hydrogenation catalysts is their vulnerability towards water produced during the reaction $[9,10]$. Unlike traditional Fischer-Tropsch reactions (FT), there are two moles of water produced for every one mole of $\mathrm{CO}_{2}$ consumed [11-13]. Water is known to oxidize active sites, hydrogenate supports, and sinter catalyst sites [14-18]. In the past, efforts have been made to protect the catalyst by adding a start-up solvent or using a gas recycling system that sufficiently removes the water from the gas on each cycle $[19,20]$. An additional route to increasing a catalyst's resistance to water is to add elements that are more resistant to oxidation. There has been some promising data that adding copper in small amounts to a supported iron catalyst can drastically improve activity [21-23]. Some modeling efforts of $\mathrm{CO}_{2}$ hydrogenation on the iron copper intermetallic (100) phase support the hypothesis that small amounts of copper will be beneficial to the system [24]. There is also extensive work on how catalysts change as a result of exposure to syngas conditions [25-29], but there is very little characterization work being done on $\mathrm{FeCu} / \mathrm{K}$ catalysts in $\mathrm{CO}_{2}$ hydrogenation conditions.

In response to this gap in the literature, we report on the activity, composition, morphology, and kinetics of adding copper to well-characterized iron-based catalysts with the aim of optimizing a new, more efficient $\mathrm{CO}_{2}$ hydrogenation catalyst in this paper. Additionally, a detailed model for the fixed-bed reactor was developed to derive and understand the kinetics governing the activity and selectivity of the iron-based catalyst-containing copper metal. The model considers mass transfer between the catalyst particles and within a given particle. The species diffuse into individual particles and react inside the pores, and exchange mass with fluid flowing within the interstitial space of the particle bed [30-32]. The model also considers heat transfer associated with exothermic reactions occurring in the particles in the fixed-bed. The fluid mixture and packed bed properties depend on temperature, composition, and porosity. The model predictions are compared to the experimental data for the catalyst-containing copper metal.

\section{Results}

To evaluate the potential benefits of adding copper to an iron-based $\mathrm{CO}_{2}$ reduction catalyst, a standard iron $\mathrm{CO}_{2}$ hydrogenation catalyst that has been covered extensively in the literature was used as the baseline catalyst matrix $[6,9,31,33,34]$.

Table 1 shows that a pure iron catalyst $(100 \mathrm{Fe} / \mathrm{K})$ has similar activity to what has been previously published for studies performed at $300{ }^{\circ} \mathrm{C}$ and $290 \mathrm{psi}[6,9,31-33]$. The overall $\mathrm{CO}_{2}$ conversion was $24 \%, 79 \%$ of which was converted into useful hydrocarbons. Methane $(5 \%)$ and carbon monoxide $(16 \%)$ made up the rest of the product stream. This leads to an overall hydrocarbon yield of $19 \%$. Hydrocarbon yield is defined as the percent of carbon atoms that fully convert into a $\mathrm{C} 2+$ hydrocarbon product. Anderson-Schultz-Flory (ASF) growth distribution plots were also used to evaluate the length distribution of the hydrocarbon chains. The chain growth probability value $(\alpha)$ for $100 \mathrm{Fe} / \mathrm{K}$ is 0.98 , which is a measure of the slope of $\ln (\mathrm{WN} / \mathrm{N})$ vs. $\mathrm{N}$, where $\mathrm{N}$ is the carbon number and $\mathrm{WN}$ is the weight fraction of hydrocarbons containing $\mathrm{N}$ carbons. The last measure used to evaluate the activity of the catalysts was the olefin/paraffin $(\mathrm{O} / \mathrm{P})$ ratio, which is simply the number of olefins products divided by the number of paraffin products. Since olefins are much easier to perform subsequent chemistry upon, higher $\mathrm{O} / \mathrm{P}$ is more desirable. The $\mathrm{O} / \mathrm{P}$ ratio for $100 \mathrm{Fe} / \mathrm{K}$ was 4.3 .

Copper was then added to the catalyst at various ratios. Iron was replaced by $10 \%(90 \mathrm{Fe} 10 \mathrm{Cu} / \mathrm{K})$, $20 \%(80 \mathrm{Fe} 20 \mathrm{Cu} / \mathrm{K})$, and $30 \%(70 \mathrm{Fe} 30 \mathrm{Cu} / \mathrm{K})$ copper while maintaining the same amount of potassium and alumina support. The total amount of active metal species (iron and copper) did not change between catalysts. Only the ratio of iron and copper was altered. In all cases, there was an increase in catalyst activity under the same conditions $\left(300^{\circ} \mathrm{C}\right.$ and $\left.290 \mathrm{psi}\right)$. The $90 \mathrm{Fe} 10 \mathrm{Cu} / \mathrm{K}$ catalyst showed the best activity, almost doubling the $\mathrm{CO}_{2}$ conversion (41\%) and increasing hydrocarbon selectivity 
(88\%). It also increased the $\mathrm{O} / \mathrm{P}$ ratio to 4.9 . As the copper:iron ratio was increased from 10 to $20 \%$, $\mathrm{CO}_{2}$ conversion decreased from 41 to $30 \%$ and hydrocarbon yield decreased in favor of the formation of more methane and $\mathrm{CO}$. Further increases in copper:iron ratio yielded an increase in $\mathrm{CO}_{2}$ conversion to $36 \%$ and similar activity and selectivity as shown for the $90 \mathrm{Fe} 10 \mathrm{Cu} / \mathrm{K}$ catalyst. The increase in hydrocarbons in these $\mathrm{FeCu} / \mathrm{K}$ samples seems to correlate with a decrease in CO selectivity. Therefore, more intermediate $\mathrm{CO}$ is being converted into full hydrocarbons, which would suggest an increase in the rate of the FT step of the reaction. The only disadvantage from the addition of copper to the iron catalyst was a slight decrease in Anderson-Shultz-Flory chain growth probability values $\alpha$ (0.98 vs. 0.90). The result of the increase in $\mathrm{CO}_{2}$ conversion and hydrocarbon selectivity leads to a huge increase in the hydrocarbon yield. The $90 \mathrm{Fe} 10 \mathrm{Cu} / \mathrm{K}$ catalyst had the highest yield of $36 \%, 70 \mathrm{Fe} 30 \mathrm{Cu} / \mathrm{K}$ had the second highest yield of $32 \%$, and $80 \mathrm{Fe} 20 \mathrm{Cu} / \mathrm{K}$ had the worst yield of the FeCu/K catalysts at $25 \%$. The discrepancy in $\mathrm{CO}_{2}$ conversion and catalyst selectivity found for $80 \mathrm{Fe} 20 \mathrm{Cu} / \mathrm{K}$ will be substantiated further in this paper.

Table 1. Activities of $\mathrm{FeCu} / \mathrm{K}$ catalysts with various $\mathrm{Fe}: \mathrm{Cu}$ ratios.

\begin{tabular}{ccccccccc}
\hline \multirow{2}{*}{ Sample } & \multirow{2}{*}{$\mathbf{C O}_{2}$ Conversion (\%) } & \multicolumn{3}{c}{ Selectivity (\%) } & \multirow{2}{*}{ O/P } & Alpha & Yield (\%) \\
\cline { 3 - 5 } & & $\mathbf{C O}$ & Meth & $\mathbf{C 2 - C 5}$ & & & \\
\hline $100 \mathrm{Fe} / \mathrm{K}$ & 24 & 16 & 4.6 & 79 & 4.29 & 0.98 & 19 \\
$90 \mathrm{Fe} 10 \mathrm{Cu} / \mathrm{K}$ & 41 & 5.7 & 6.4 & 88 & 4.88 & 0.91 & 36 \\
$80 \mathrm{Fe} 20 \mathrm{Cu} / \mathrm{K}$ & 30 & 6.3 & 9.7 & 84 & 5.52 & 0.89 & 25 \\
$70 \mathrm{Fe} 30 \mathrm{Cu} / \mathrm{K}$ & 36 & 5.7 & 6.0 & 88 & 4.06 & 0.91 & 32 \\
\hline
\end{tabular}

Table 2 provides preliminary results that support literature findings on the necessity of adding potassium to the catalyst matrix to achieve higher catalyst activity [24,32,33]. Without the addition of potassium to the catalyst matrix, $\mathrm{CO}_{2}$ conversion drops to $17 \%$ and both the methane (35\%) and carbon monoxide (11\%) selectivities increase (Table 2 ). In addition, the hydrocarbon selectivity decreases to $54 \%$ and the hydrocarbons formed are completely saturated. Since no olefins were formed from catalysts without potassium present in the catalyst matrix, the $\mathrm{O} / \mathrm{P}$ ratio was zero. This further highlights the role potassium has on iron-based catalyst activity.

Table 2. Effects of $\mathrm{K}$ on $\mathrm{FeCu} / \mathrm{K}$ catalysts.

\begin{tabular}{lcccccccc}
\hline \multirow{2}{*}{ Sample } & \multirow{2}{*}{$\mathbf{C O}_{2}$ Conversion (\%) } & \multicolumn{3}{c}{ Selectivity (\%) } & \multirow{2}{*}{ O/P } & \multirow{2}{*}{ Alpha } & \multirow{2}{*}{ Yield (\%) } \\
\cline { 3 - 6 } & & $\mathbf{C O}$ & Meth & C2-C5 & & & \\
\hline $\mathrm{Fe} 80 \mathrm{Cu} 20 / \mathrm{K}$ & 30 & 6 & 10 & 84 & 5.5 & 0.89 & 25 \\
$\mathrm{Fe} 80 \mathrm{Cu} 20 / \mathrm{noK}$ & 17 & 35 & 11 & 54 & 0 & 0.69 & 9.3 \\
\hline
\end{tabular}

In order to determine whether the FeCu oxide phase was critical to the observed increase in activity, a sample was tested that consisted of a physically mixed $100 \mathrm{Fe} / \mathrm{K}$ catalyst and $100 \mathrm{Cu} / \mathrm{K}$ catalyst in the same ratio as the $90 \mathrm{Fe} 10 \mathrm{Cu} / \mathrm{K}$ and the results were compared (Table 3 ). This physically mixed sample contained the same amount of all the elements in the previous samples but did not share any effects due to copper and iron being on the same supported substrate. The physically mixed sample showed a drop in $\mathrm{CO}_{2}$ conversion of $18 \%$, less than $50 \%$ of what the $90 \mathrm{Fe} 10 \mathrm{Cu} / \mathrm{K}$ sample displayed. Methane selectivity increased to $14 \%$, and CO selectivity dropped to $3 \%$. No olefins were produced in the mixed sample, and the $\alpha$ value dropped from 0.95 to 0.75 . With such a drastic change in activity, it is clear that the Fe and $\mathrm{Cu}$ reagents must have some cooperative effect when they are precipitated on the same support. To determine if a simultaneous deposition of $\mathrm{Cu}$ and Fe was necessary for this synergistic effect, a "layered" catalyst containing Fe and Cu was also synthesized in a step-wise fashion. In the "layered" sample, the iron and potassium portions were nucleated onto the 
support and calcined, then the copper solution was added, dried, and calcined (Table 3). No significant differences were observed between the co-precipitation and sequentially precipitated samples beyond an increase in $\mathrm{O} / \mathrm{P}$ ratio.

Table 3. Comparison of activities between the Fe90Cu10/K sample, a physical mixture of Fe100/K and $\mathrm{Cu} 100 / \mathrm{K}$, and a layered sample.

\begin{tabular}{ccccccccc}
\hline \multirow{2}{*}{ Sample } & \multirow{2}{*}{$\mathbf{C O}_{2}$ Conversion (\%) } & \multicolumn{3}{c}{ Selectivity (\%) } & \multirow{2}{*}{ O/P } & Alpha & \multirow{2}{*}{ Yield (\%) } \\
\cline { 3 - 5 } & & $\mathbf{C O}$ & Meth & $\mathbf{C} 2-\mathbf{C 5}$ & & & \\
\hline 90Fe10Cu/K & 38 & 9.0 & 4.8 & 86 & 4.5 & 0.95 & 32 \\
Physical mixture & 18 & 2.8 & 15 & 82 & 0 & 0.75 & 15 \\
Layered sample & 37 & 8.1 & 6.6 & 85 & 6.0 & 0.86 & 35 \\
\hline
\end{tabular}

Temperature effects were also studied to determine the kinetic parameters of a Fe80Cu20/K catalyst. Table 4 shows that at $250{ }^{\circ} \mathrm{C}$, the $\mathrm{CO}_{2}$ conversion drops to a third of its value at $300{ }^{\circ} \mathrm{C}$. When the temperature is increased to $340{ }^{\circ} \mathrm{C}$, the conversion increases as well. Carbon monoxide selectivity drops below the detection limit at the lower temperature, but at a higher temperature there is only a minor increase in $\mathrm{CO}$ and methane. The loss in activity at low temperature is consistent with that reported by Pendyala et al. [35] due to increased water oxidation of the iron catalyst during the Fischer Tropsch Synthesis (FTS) step.

Table 4. Relationship between temperature and activity for Fe80Cu20/K.

\begin{tabular}{|c|c|c|c|c|c|c|c|c|}
\hline \multirow{2}{*}{ Sample } & \multirow{2}{*}{ Temperature $\left({ }^{\circ} \mathrm{C}\right)$} & \multirow{2}{*}{$\mathrm{CO}_{2}$ Conversion $(\%)$} & \multicolumn{3}{|c|}{ Selectivity (\%) } & \multirow{2}{*}{$\mathrm{O} / \mathrm{P}$} & \multirow{2}{*}{ Alpha } & \multirow{2}{*}{ Yield (\%) } \\
\hline & & & $\mathrm{CO}$ & Meth & $\mathrm{C} 2-\mathrm{C} 5$ & & & \\
\hline \multirow[t]{3}{*}{$80 \mathrm{Fe} 20 \mathrm{Cu} / \mathrm{K}$} & 250 & 12 & 0 & 11 & 89 & 1.9 & 0.82 & 10 \\
\hline & 300 & 30 & 6.3 & 9.7 & 84 & 5.5 & 0.89 & 25 \\
\hline & 340 & 41 & 8.8 & 7.9 & 83 & 4.5 & 0.88 & 34 \\
\hline
\end{tabular}

\section{Discussion}

\subsection{Catalyst Characterization}

Catalysts were characterized by XRD (Figure 1) and XPS (Figure 2) both before and after hydrogenation. There is relatively little difference in the XRD patterns between the different catalysts. The majority of the reflections in these samples both before and after hydrogenation are accounted for by gamma- $\mathrm{Al}_{2} \mathrm{O}_{3}$, the support material. The pre-hydrogenation catalysts also show a fully oxidized $\mathrm{Fe}_{2} \mathrm{O}_{3}$ phase and $\mathrm{KO}_{2}$ phase (Figure 1a). Although $\mathrm{K}_{2} \mathrm{O}$ is the standard phase of potassium oxide, we consistently observe the $\mathrm{KO}_{2}$ phase, which is indicative of how the potassium arranges itself in the catalyst matrix.

After reduction and subsequent $\mathrm{CO}_{2}$ hydrogenation (Figure 1b), the $\mathrm{Fe}_{2} \mathrm{O}_{3}$ phase shifts to the reduced $\mathrm{Fe}_{3} \mathrm{O}_{4}$ inverse spinel phase, and in samples with a higher copper ratio some metallic face center cubic (FCC) phase begins to form as well. It is important to note that, although the crystal phases used for simulation are Fe-based, the reality is that they are likely Fe-Cu intermetallic or alloy phases. The small difference in atomic radius between the two atoms and the complex nature of the catalyst make differentiation of those phases difficult in this system. As the $\mathrm{Cu}$ ratio is increased, the metallic FCC phase also increases. One possible explanation is that the higher reduction potential of $\mathrm{Cu}$ leads to an increase in the metallic phase in the reductive environment. Although some reduction should be expected due to the presence of $\mathrm{H}_{2}$, there does not appear to be a correlation between the increase in the FCC phase and an increase in catalytic activity for $\mathrm{CO}_{2}$ hydrogenation. This result differs from the modeling [24-29] precedent, which uses the metallic FCC phase as a catalytically active site in $\mathrm{Fe}_{\mathrm{x}} \mathrm{Cu}_{\mathrm{y}}$ catalyst. In the highest performing catalyst, $90 \mathrm{Fe} 10 \mathrm{Cu} / \mathrm{K}$, there is no evidence of the metallic phase. 
It is only when the copper, which has a much larger reduction potential than iron, ratio increases that the oxide transitions reduces fully to the metal.

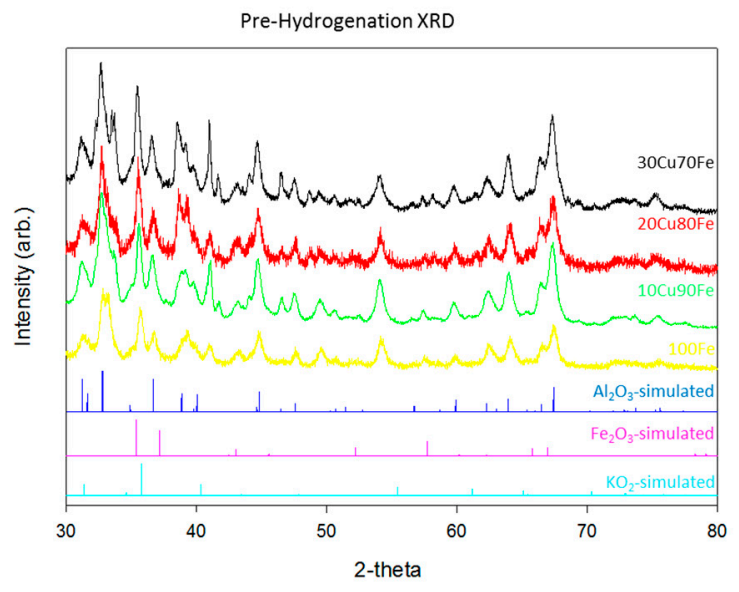

(a)

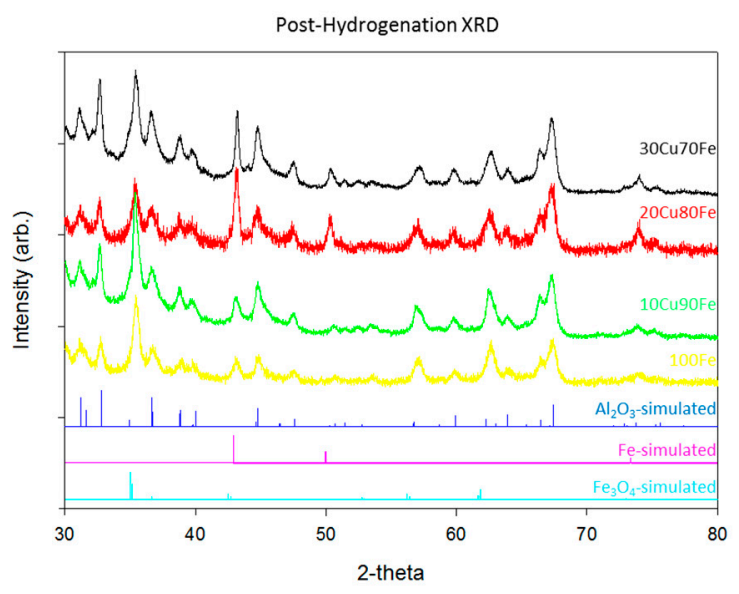

(b)

Figure 1. (a) Powder X-ray diffraction patterns of $100 \mathrm{Fe} / \mathrm{K}$ (orange), $90 \mathrm{Fe} 10 \mathrm{Cu} / \mathrm{K}$ (grey), $80 \mathrm{Fe} 20 \mathrm{Cu} / \mathrm{K}$ (light blue), and $70 \mathrm{Fe} 30 \mathrm{Cu} / \mathrm{K}$ (dark blue) after calcination but before reduction and $\mathrm{CO}_{2}$ hydrogenation . For comparison, simulated patterns for $\gamma-\mathrm{Al}_{2} \mathrm{O}_{3}$ (yellow), $\mathrm{KO}_{2}$ (blue), and $\mathrm{Fe}_{2} \mathrm{O}_{3}$ (green) are also shown; (b) Powder X-ray diffraction patterns of 100Fe/K (grey), 90Fe10Cu/K (light blue), 80Fe20Cu/K (orange), and $70 \mathrm{Fe} 30 \mathrm{Cu} / \mathrm{K}$ (dark blue) after $\mathrm{CO}_{2}$ hydrogenation. For comparison, simulated patterns for $\gamma-\mathrm{Al}_{2} \mathrm{O}_{3}$ (yellow), $\mathrm{Fe}$ (blue), and $\mathrm{Fe}_{3} \mathrm{O}_{4}$ (green) are also shown.

XPS also shows little difference between the $\mathrm{Fe} / \mathrm{K}$ and $\mathrm{FeCu} / \mathrm{K}$ samples (Figure 2). The $\mathrm{Fe} \_2 \mathrm{p}$ analysis shows a minor shift $(2-3 \mathrm{eV})$ toward a more reductive environment with the addition of copper. The $\mathrm{Cu} \_2 \mathrm{p}$ pre-reduction samples show peaks at $943 \mathrm{eV}$ that are due to the presence of $\mathrm{Cu}^{2+}$. After reduction, these peaks disappear and the peaks at $934 \mathrm{eV}$ shift $3-4 \mathrm{eV}$, which is a more reduced form of copper.

Fe_2pXPS

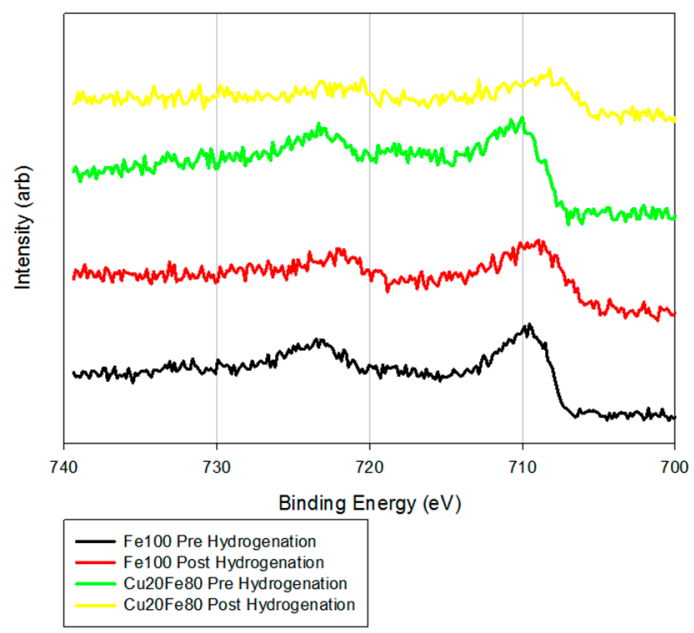

(a)
Cu_2pXPS

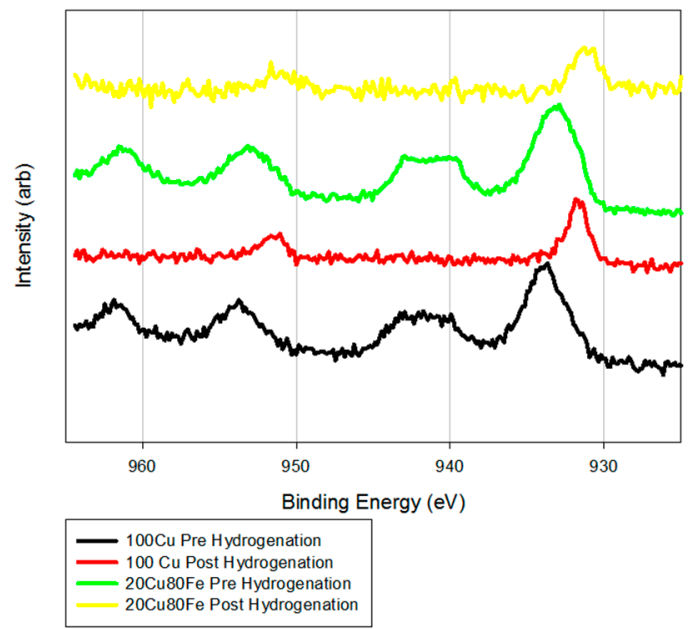

(b)

Figure 2. X-ray photoelectron spectroscopy data for both (a) Fe_2p and (b) Cu_2p.

The morphology of the system was examined by SEM-EDS. The analysis was performed on the catalyst samples both before and after hydrogenation (Figure 3). All samples observed before 
hydrogenation showed even distributions of copper and iron across the sample. However, in the post-hydrogenation samples, as the concentration of copper increases, the phase separation becomes evident. The $90 \mathrm{Fe} 10 \mathrm{Cu} / \mathrm{K}$ post-hydrogenation sample still shows an evenly distributed amount of Fe and $\mathrm{Cu}$ across the particle, with some copper-rich and iron-rich areas. The $80 \mathrm{Fe} 20 \mathrm{Cu} / \mathrm{K}$ post-hydrogenation sample shows the appearance of large copper-rich areas where almost no iron can be found. As the samples reach peak copper concentration in the $70 \mathrm{Fe} 30 \mathrm{Cu} / \mathrm{K}$ catalyst, we again see an even distribution of copper, but the copper signal is much stronger than that of the iron sample, implying that there is much more copper at the surface of the particle than there is iron. The most likely explanation of this would be a copper-rich layer coating the iron oxide bulk. This observation along with the XRD results is likely due to the immiscibility between metallic iron and metallic copper. It is hypothesized that copper is only miscible in the $\mathrm{Fe}_{3} \mathrm{O}_{4}$ inverse spinel phase to around $10 \%$, and then begins to migrate out of the lattice under the conditions of $\mathrm{CO}_{2}$ hydrogenation [34,36]. Once on the surface, it would be much easier to reduce the individual copper atoms and metallic copper would form. Once enough metallic copper forms (around the 30\% mark), it would begin to coat the surface entirely, suppressing the EDS signal for iron.

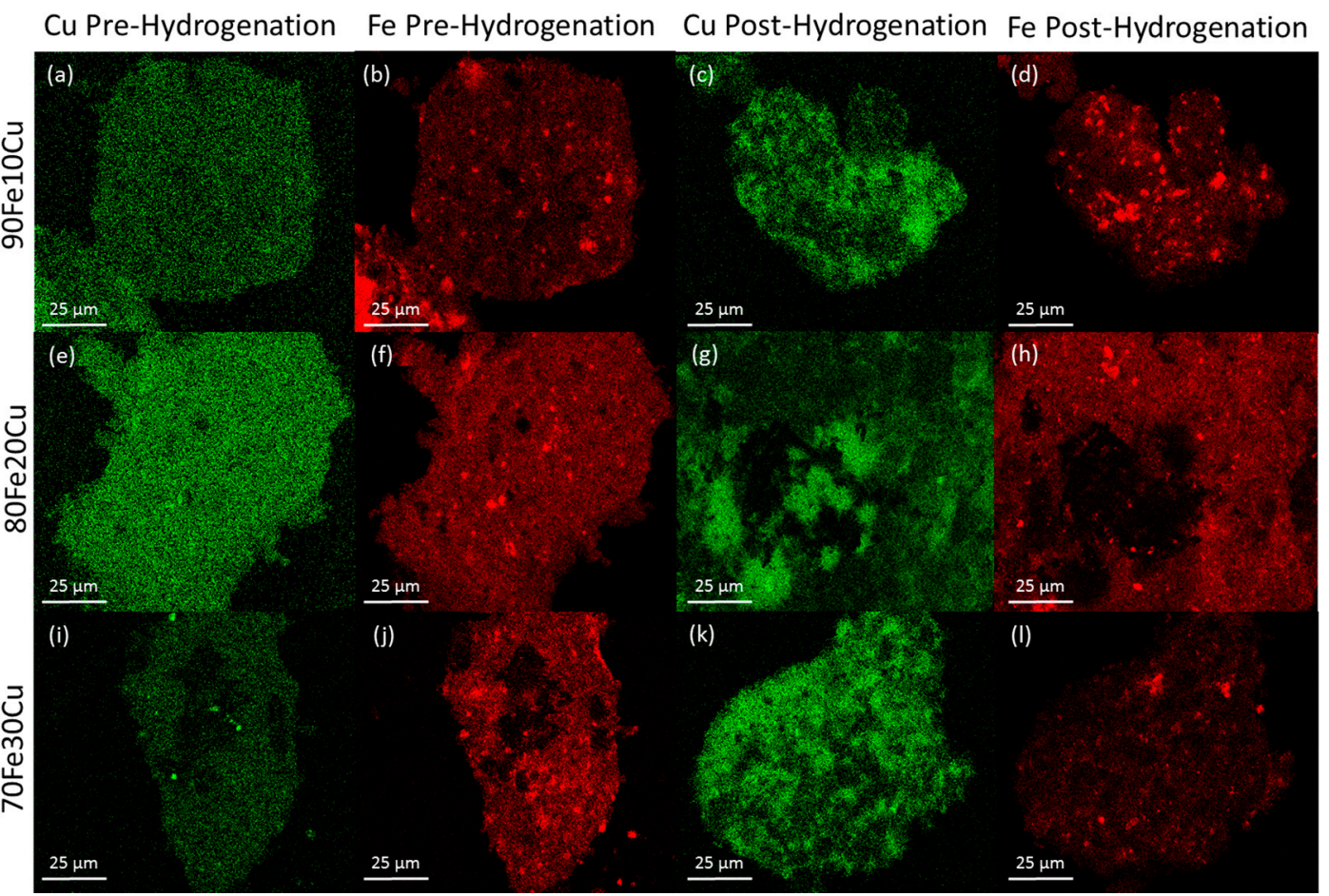

Figure 3. SEM-EDS mapping data where copper is labeled green and iron is labeled blue. (a) $90 \mathrm{Fe} 10 \mathrm{Cu} / \mathrm{K}$ copper map pre-hydrogenation; (b) $90 \mathrm{Fe} 10 \mathrm{Cu} / \mathrm{K}$ iron map pre-hydrogenation; (c) $90 \mathrm{Fe} 10 \mathrm{Cu} / \mathrm{K}$ copper map post-hydrogenation; (d) $90 \mathrm{Fe} 10 \mathrm{Cu} / \mathrm{K}$ iron map post-hydrogenation;

(e) $80 \mathrm{Fe} 20 \mathrm{Cu} / \mathrm{K}$ copper map pre-hydrogenation; (f) $80 \mathrm{Fe} 20 \mathrm{Cu} / \mathrm{K}$ iron map pre-hydrogenation;

(g) $80 \mathrm{Fe} 20 \mathrm{Cu} / \mathrm{K}$ copper map post-hydrogenation; (h) $80 \mathrm{Fe} 20 \mathrm{Cu} / \mathrm{K}$ iron map post-hydrogenation;

(i) $70 \mathrm{Fe} 30 \mathrm{Cu} / \mathrm{K}$ copper map pre-hydrogenation; (j) $70 \mathrm{Fe} 30 \mathrm{Cu} / \mathrm{K}$ iron map pre-hydrogenation;

(k) $70 \mathrm{Fe} 30 \mathrm{Cu} / \mathrm{K}$ copper map post-hydrogenation; and (1) $70 \mathrm{Fe} 30 \mathrm{Cu} / \mathrm{K}$ iron map post-hydrogenation.

\subsection{Computational Modeling}

A three-dimensional, non-isothermal, fixed-bed reactor model was developed by solving energy and convective-diffusion equations, which are coupled with Navier-Stokes equations for gas flow in a porous media, using a multiphysics modeling software, (COMSOL Inc., Burlington, VT, USA). The catalyst bed consists of particles, which are represented by a sub-grid model (Reactive Pellet Model) available in COMSOL. The sub-grid model describes the diffusion and reactions occurring 
inside a particle. The Millington-Quirk model is used to calculate the diffusivities of species inside a particle as functions of particle porosity. The surface area $\left(22 \mathrm{~m}^{2} / \mathrm{g}\right)$ and pore volume $(0.1638 \mathrm{~mL} / \mathrm{g})$ were determined via BET analysis. The species concentrations outside the particles (within the catalyst bed) are influenced by the chemical reactions occurring inside the particles. The sub-grid model was coupled to the fixed-bed model through a boundary condition that exchanges mass between gas outside the particle at a given location in the bed and inside the particle volume. Figure 4 shows the fixed-bed reactor geometry and the contours of $\mathrm{C}_{3} \mathrm{H}_{6}$ concentration in $\mathrm{mol} / \mathrm{m}^{3}$ at $300{ }^{\circ} \mathrm{C}$ predicted by the model. The model considers only the rate controlling steps, and includes the formation of propene and methane, where the propene represents all the saturated and unsaturated hydrocarbon species $(\mathrm{C} 2-\mathrm{C} 5+)$ measured in the experiments following Riedel et al. [30]. The thermodynamic and transport properties of each species are calculated using the CHEMKIN database as functions of temperature and composition. The mixture properties are calculated from the species properties based on local composition. The reactor is identical to the one employed in the experiments, which is a $0.0094 \mathrm{~m}$ inner diameter tube of $0.305 \mathrm{~m}$ length. It has inlet and outlet sections $(0.0254 \mathrm{~m}$ each) and a middle section, which is filled with $20 \mathrm{~g}$ catalyst containing $(\mathrm{FeCu}) / \mathrm{K} /$ Aumina $16 \mathrm{M}: 12 \mathrm{~K}: 100 \mathrm{Al}_{2} \mathrm{O}_{3}$ by weight. In calculating the gas hourly space velocity (GHSV), only the total metal weight, mcat, $2.19 \mathrm{~g}$ was used. Figure 4 shows zero $\mathrm{C}_{3} \mathrm{H}_{6}$ concentration near the entrance of the catalyst bed, and the concentration increases from the inlet to the outlet of the reactor as the FT reactions forming the hydrocarbons continue to occur along the entire bed.

The steady-state, three-dimensional, convective-diffusion equations are given by

$$
\nabla \cdot\left(-D_{j} \cdot C_{j}\right)+u \cdot \nabla C_{j}=0
$$

where $D_{j}$ is the diffusion coefficient of species $\mathrm{j}$ in hydrogen, which is the dominant species in the gas mixture. Hydrogen is chosen to represent the mixture for calculating pseudo-binary diffusion coefficients. $C_{j}$ is the concentration of species $j$. Equation (1) describes the mass transport occurring within the interstitial space of the fixed-bed reactor. Equation (1) does not include diffusion and chemical reactions occurring inside a particle, which will be considered in a sub-grid model. The velocity vector, $\mathrm{u}$, is obtained by solving the Navier-Stokes equations, which are given by

$$
\rho \nabla \cdot u=0
$$

and

$$
\rho(u \cdot \nabla) u=\nabla \cdot\left[-p I+\mu\left((\nabla u)+(\nabla u)^{T}\right)\right]
$$

where $\rho, \mu$, and $p$ are the density, dynamic viscosity, and pressure of the gas mixture, respectively. $I$ is the identity vector, and the superscript " $T$ " represents transpose. Equations (1)-(3) are applied for the entire reactor, including the inlet and outlet sections, where a free flow of gases occurs. For the fixed-bed in the middle section of the reactor, the momentum equation (Darcy-Brinkman) for the porous media is given by

$$
\begin{gathered}
\frac{\rho}{\varepsilon_{p}}(u \cdot \nabla) \frac{u}{\varepsilon_{p}}=\nabla \cdot\left[-p I+\frac{\mu}{\varepsilon_{p}}\left((\nabla u)+(\nabla u)^{T}\right)-\frac{2 \mu}{3 \varepsilon_{p}}(\nabla \cdot u) I\right]-\left(\mu K^{-1}+\frac{\rho}{\varepsilon_{p}^{2}}(\nabla \cdot u)\right) u . \\
\varepsilon_{p}=1-\frac{\rho_{\text {bed }}}{\rho_{\text {support }}}
\end{gathered}
$$

Here, $\varepsilon_{p}$ and $K$ are the porosity and isotropic permeability of the fixed-bed, respectively. The gases flow within the interstitial volume of the bed. The porosity of the bed, $\varepsilon_{p}$, was set at 0.51 , and the permeability, $K$, was set at $5 \times 10^{-12} \mathrm{~m}^{2}$. The porosity was calculated from Equation (5), where $\rho_{\text {support }}$ $\left(2260.0 \mathrm{~kg} / \mathrm{m}^{3}\right)$ and $\rho_{\text {bed }}\left(1105 \mathrm{~kg} / \mathrm{m}^{3}\right)$ are the bulk density of the alumina support and the density 
of the catalyst bed, respectively. The density, $\rho_{b e d}$, of the catalyst bed is given by the mass of the bed $(0.02 \mathrm{~kg})$ divided by the volume of the bed, $V_{\text {reactor }}\left(1.81 \times 10^{-5} \mathrm{~m}^{3}\right)$.

The fixed-bed is assumed to be made of mono-dispersed spherical particles containing metal catalyst and having radius, $r_{p r}(250 \mu \mathrm{m})$. An individual particle has a porosity of $\varepsilon_{p r}$, wherein the gases can diffuse but the convective flow within the micro-sized pores of the particle is neglected. The species concentration, $C_{j}$, at a given position within the bed is influenced by the diffusion and chemical reactions occurring inside the particles. A sub-grid model equation describing the species concentration, $C_{p r, j}$, distributions inside the pores of a spherical particle is given by

$$
\left[3 V_{\text {reactor }} \varepsilon_{p} / r_{p r}^{3}\right]\left[r^{2} r_{p r}^{2} \varepsilon_{p r} \frac{\partial C_{p r, j}}{\partial t}+\nabla \cdot\left(-r^{2} D_{p r, j} \nabla C_{p r, j}\right)=r^{2} r_{p r}^{2} R_{p r, j}\right]
$$

where $r$ is the radial distance within a spherical particle and the diffusion coefficients, $D_{p r, j}$, are given by

$$
D_{p r, j}=\varepsilon_{p r}^{4 / 3} D_{j}
$$

where the particle porosity is given by

$$
\varepsilon_{p r}=1-\frac{\rho_{\text {support }}}{\rho_{\text {solid }}} .
$$

Here, $\rho_{\text {solid }}\left(3650 \mathrm{~kg} / \mathrm{m}^{3}\right)$ is the solid material density of alumina and is higher than the bulk density, $\rho_{\text {support }}$, of the particles. The particle porosity, $\varepsilon_{p r}$, is calculated to be 0.38 , which when divided by $\rho_{\text {support }}$ gives a pore volume of $0.1681 \mathrm{~mL} / \mathrm{g}$. The calculated pore volume of $0.1681 \mathrm{~mL} / \mathrm{g}$ is close to the measured BET value of $0.1638 \mathrm{~mL} / \mathrm{g}$.

The gases enter the reactor at ambient temperature and get heated because the reactor walls are maintained at a constant temperature $T_{w}$. The energy equation describes the temperature, $T$, distribution inside the fixed-bed reactor, and is given by

$$
\left(\rho C_{p}\right)_{e f f} u \cdot \nabla T+\nabla \cdot q=\sum_{j} R_{p r, j} h_{j}
$$

where

$$
\left(\rho C_{p}\right)_{e f f}=\varepsilon_{\text {total }} \rho C_{p}+\left(1-\varepsilon_{\text {total }}\right) \rho_{\text {solid }} C_{p, \text { solid }}
$$

the heat flux, $q$, is

$$
q=-k_{e f f} \nabla T,
$$

the effective thermal conductivity is

$$
k_{e f f}=\varepsilon_{\text {total }} k+\left(1-\varepsilon_{\text {total }}\right) k_{\text {solid }}
$$

the total porosity of the bed is

$$
\varepsilon_{\text {total }}=1-\frac{\rho_{\text {bed }}}{\rho_{\text {solid }}}
$$

where the thermal conductivity, $k_{\text {solid }}$, and specific heat, $C_{p, \text { solid }}$, of the solid support material are $18 \mathrm{~W} / \mathrm{mK}$ and $880 \mathrm{~J} / \mathrm{kg} \cdot \mathrm{K}$, respectively. The enthalpies of species, $h_{j}$, are obtained from the CHEMKIN database. The ideal gas law was also used. The flow rates and composition of reactants at the inlet and the pressure at the outlet were specified as boundary conditions.

The reaction rates, $R_{p r, j}$, are given by

$$
R_{p r, \mathrm{CO} 2}=-k S H\left(\mathrm{CO}_{2} \times \mathrm{H}_{2}-\left(\frac{\mathrm{CO} \times \mathrm{H}_{2} \mathrm{O}}{\mathrm{K}_{e q}}\right)\right),
$$




$$
\begin{gathered}
R_{p r, \mathrm{H} 2}=-2 k S H\left(\mathrm{CO}_{2} \times \mathrm{H}_{2}-\left(\frac{\mathrm{CO} \times \mathrm{H}_{2} \mathrm{O}}{\mathrm{K}_{e q}}\right)\right)-2 k F T \times \mathrm{CO} \times \mathrm{H}_{2}-3 \times k F T s \times \mathrm{CO} \times \mathrm{H}_{2}, \\
R_{p r, \mathrm{H} 2 \mathrm{O}}=k S H\left(\mathrm{CO}_{2} \times \mathrm{H}_{2}-\left(\frac{\mathrm{CO} \times \mathrm{H}_{2} \mathrm{O}}{\mathrm{K}_{e q}}\right)\right)+k F T \times \mathrm{CO} \times \mathrm{H}_{2}+k F T s \times \mathrm{CO} \times \mathrm{H}_{2}, \\
R_{p r, \mathrm{CO}}=k S H\left(\mathrm{CO}_{2} \times \mathrm{H}_{2}-\left(\frac{\mathrm{CO} \times \mathrm{H}_{2} \mathrm{O}}{K_{e q}}\right)\right)-k F T \times \mathrm{CO} \times \mathrm{H}_{2}-k F T s \times \mathrm{CO} \times \mathrm{H}_{2}, \\
R_{p r, \mathrm{C} 3 \mathrm{H} 6}=k F T \times \mathrm{CO} \times \mathrm{H}_{2},
\end{gathered}
$$

where the kinetic constants are given by

$$
\begin{gathered}
k S H=\frac{\rho_{\text {cat }} R_{g} T k_{S H 0} \exp \left[-E_{S H} / R_{g} T\right]}{\left[(\mathrm{CO})+a_{S H H 2 O}\left(H_{2} \mathrm{O}\right)+b_{S H C O 2}\left(C O_{2}\right)\right]^{\prime}}, \\
k F T=\frac{\rho_{\text {cat }} R_{g} T k_{F T 0} \exp \left[-E_{F T} / R_{g} T\right]}{\left[(\mathrm{CO})+a_{F T H 2 O}\left(H_{2} \mathrm{O}\right)+b_{F T C O 2}\left(\mathrm{CO}_{2}\right)\right]^{\prime}}, \\
k F T s=\frac{\rho_{\text {cat }} R_{g} T k_{F T s 0} \exp \left[-E_{F T s} / R_{g} T\right]}{\left[(\mathrm{CO})+a_{F T s H 2 O}\left(H_{2} O\right)+b_{F T s C O 2}\left(\mathrm{CO}_{2}\right)\right]^{\prime}}, \\
K_{\text {eq }}=K_{\text {eq0 } 0} 10^{\left(2.029-\frac{2073}{T}\right)}, \\
\rho_{\text {cat }}=m_{\text {cat }} / V_{\text {reactor }} .
\end{gathered}
$$

The gas hourly space velocity, GHSV, is given by

$$
G H S V=F_{\text {total }} / m_{\text {cat }} \text {. }
$$

In this study, GHSV is defined by Equation (24), where $F_{\text {total }}$ is the sum of the hydrogen and $\mathrm{CO}_{2}$ volumetric flow rates entering the reactor at standard conditions. Here, $m_{\text {cat }}$ is the weight $(2.19 \mathrm{~g})$ of the total elemental metal content in the catalyst without the support material. $V_{\text {reactor }}$ is the volume of the middle section of the reactor containing the fixed catalyst bed, and $T$ is its temperature. $R_{g}$ is the gas constant. The species concentrations are represented by $\mathrm{H}_{2}, \mathrm{CO}_{2}, \mathrm{CO}, \mathrm{H}_{2} \mathrm{O}, \mathrm{C}_{3} \mathrm{H}_{6}$, and $\mathrm{CH}_{4}$. Propene is used as the representative species for all the hydrocarbons $(\mathrm{C} 2-\mathrm{C} 5+)$ produced in the experiments with the exception of $\mathrm{CH}_{4}$, following the work of Riedel et al. [31]. The values for the kinetic parameters used in the model are provided in Table 5.

The $\mathrm{CO}, \mathrm{CH}_{4}$, and $\mathrm{C} 2-\mathrm{C} 5+$ yields and selectivities are defined based on atomic carbon rather than on a molar basis. For example, the molar concentration of propene is multiplied by three in calculating its yield and selectivity because it contains three atomic carbons. As usual, $\mathrm{CO}_{2}$ conversion is the reacted $\mathrm{CO}_{2}$ as a percent of $\mathrm{CO}_{2}$ in the feed stream, and product selectivity is calculated as a percent of reacted $\mathrm{CO}_{2}$. Multiplying the conversion with the selectivity of the product gives the yield.

The transient model Equations (1)-(24) are solved for $1000 \mathrm{~s}$ until steady-state solutions are achieved. Figure 5 shows the model predictions for the contours of propene concentration in the fixed-bed reactor for the reactor conditions, reactant flows (GHSV), and catalyst compositions used in the experiments as discussed in the previous section. Figure 5 shows the predicted contours of $\mathrm{C}_{3} \mathrm{H}_{6}$ formation rate $\left(<0.19 \mathrm{~mol} /\left(\mathrm{m}^{3} \mathrm{~s}\right)\right)$ due to the hydrogentaion reactions, and it shows a decreasing rate with distance along the reactor length, unlike the $\mathrm{C}_{3} \mathrm{H}_{6}$ concentration contours shown in Figure 4, which exhibit the opposite trend as one might expect. Figure 6 shows the predicted contours of $\mathrm{C}_{3} \mathrm{H}_{6}$ concentration and the rate of formation within a single catalyst pellet at $5 \mathrm{~cm}$ from the entrance of the reactor. The $\mathrm{C}_{3} \mathrm{H}_{6}$ concentration changes only very slightly across the radius of the spherical pellet because of a relatively fast diffusion of the gaseous species in and out of the pellet. $\mathrm{The}_{3} \mathrm{C}_{6}$ formation rate predicted by the model is uniform across the pellet. We performed simulations for different particle sizes, and found that the uniform profiles for $\mathrm{C}_{3} \mathrm{H}_{6}$ hold for particle sizes up to $1 \mathrm{~cm}$ in diameter. 
So, it is clear that the model predictions are not very sensitive to the particle size. However, conversion and yields are sensitive to particle porosity despite fast diffusion within a particle. We increased the particle porosity with a total porosity $\left(\varepsilon_{\text {total }}\right)$ fixed at $69.7 \%$ and a fixed catalyst loading such that the bed porosity decreases correspondingly. As the particle porosity is increased, more surface area becomes available for chemical reactions, affecting the conversion and yields as shown in Figure 7. Figure 8 shows the profiles of conversion and product yields along the length of the reactor for the $20 \mathrm{Cu} / 80 \mathrm{Fe} / \mathrm{K}$ catalyst bed. Our simulations show that the species concentrations inside catalyst pellets also follow almost identical profiles, as shown in Figure 8, because of negligible gradients across the catalyst pellet. Figure 9 shows the temperature profile along the center line of the reactor. Figure 9 indicates that the radial heat transfer is fast enough that the gases are heated very quickly from ambient temperature to the reactor wall temperature prior to entering the catalyst bed.
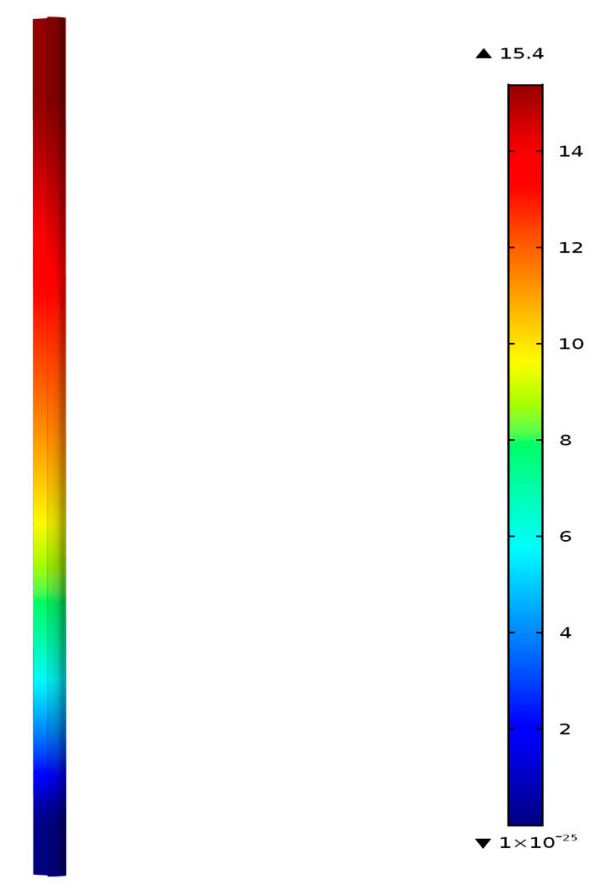

Figure 4. Reactor geometry with model-predicted contours of $\mathrm{C}_{3} \mathrm{H}_{6}$ concentration, $\mathrm{mol} / \mathrm{m}^{3}$, formed by carbon dioxide hydrogenation in the catalyst bed $(20 \mathrm{Cu} 80 \mathrm{Fe} / \mathrm{K})$ with bed porosity of 0.51 and particle porosity of 0.38 at $300{ }^{\circ} \mathrm{C}$ and 20 bar total pressure at the reactor outlet.

Table 5. Kinetic parameters used for the modeling of $80 \mathrm{Fe} 20 \mathrm{Cu} / \mathrm{K}$.

\begin{tabular}{cccc}
\hline Kinetic Parameter & $\mathbf{C O}_{2}$ Shift (SH) & FT & FTs, Methanation \\
\hline$a_{i}, \mathrm{H}_{2} \mathrm{O}$ & 65 Ref. [31] & 33 Ref. [31] & 33 Ref. [31] \\
$b_{i}, \mathrm{CO}_{2}$ & 7.4 Ref. [31] & 2.7 Ref. [31] & 2.7 Ref. [31] \\
$k_{i, 0}, \mathrm{~mol} /(\mathrm{s} \cdot \mathrm{g} \cdot \mathrm{MPa})$ & 10 Ref. [10] & $6.45 \times 10^{3}$ & $7.74 \times 10^{2}$ \\
$K_{e q 0}$ & 1 Ref. [31] & N $/ \mathrm{A}$ & N/A \\
$E_{A, i}, \mathrm{~kJ} / \mathrm{mol}$ & 55 Ref. [31] & 72 Ref. [31] & 72 Ref. [31] \\
\hline
\end{tabular}

FT: Fischer-Tropsch reaction. 


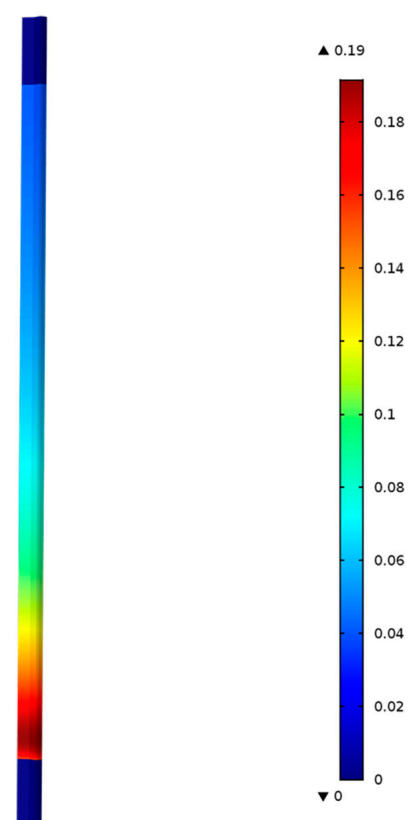

Figure 5. Contours of propene formation rate $\mathrm{mol} /\left(\mathrm{m}^{3} \mathrm{~s}\right), \mathrm{RC}_{3} \mathrm{H}_{6}$, at $300{ }^{\circ} \mathrm{C}$ and 20 bar total pressure.
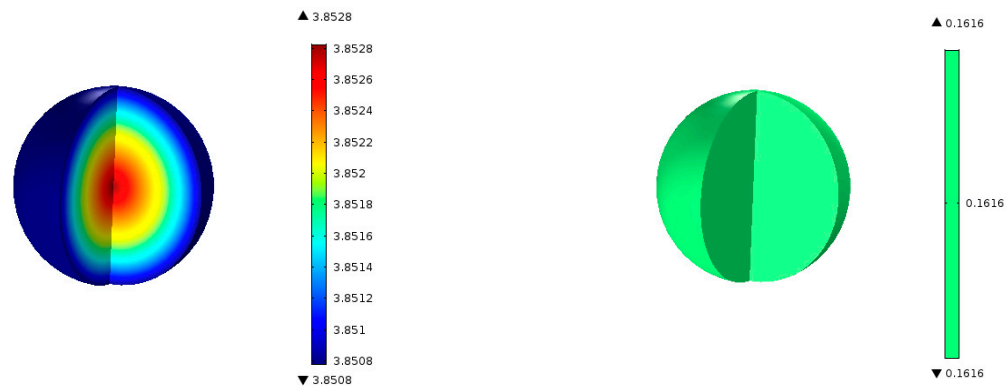

Figure 6. Contours of $\mathrm{C}_{3} \mathrm{H}_{6}$ concentration $\left(\mathrm{mol} / \mathrm{m}^{3}\right)$ and formation rate, $\mathrm{RC}_{3} \mathrm{H}_{6}\left(\mathrm{~mol} /\left(\mathrm{m}^{3} \mathrm{~s}\right)\right)$, inside a $250 \mu \mathrm{m}$ radius spherical catalyst pellet $(80 \mathrm{Fe} 20 \mathrm{Cu} / \mathrm{K})$ at $50 \mathrm{~mm}$ from the inlet show very small gradients due to high diffusion coefficients of the gas species at $300{ }^{\circ} \mathrm{C}$ and 20 bar total pressure.

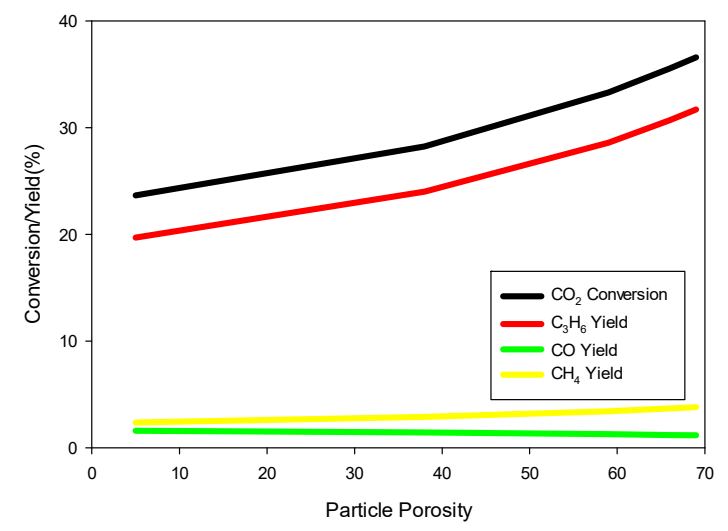

Figure 7. Effects of increased particle porosity and decreased bed porosity (with total porosity fixed at $69.7 \%$ ) on percent $\mathrm{CO}_{2}$ conversion (black), and percent $\mathrm{C}_{3} \mathrm{H}_{6}$ (red), $\mathrm{CH}_{4}$ (yellow), and $\mathrm{CO}$ (green) at the reactor outlet as predicted by the model for a fixed $20 \mathrm{~g}$ of $80 \mathrm{Fe} 20 \mathrm{Cu} / \mathrm{K}$ catalyst at $300{ }^{\circ} \mathrm{C}$ and 20 bar total pressure. 


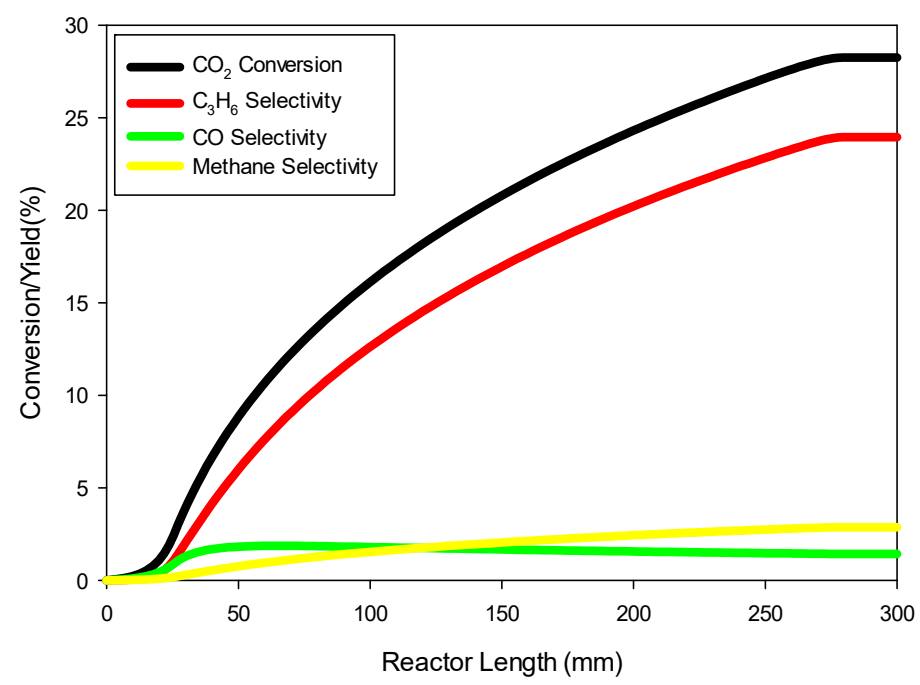

Figure 8. Profiles of percent $\mathrm{CO}_{2}$ conversion (black), and percent $\mathrm{C}_{3} \mathrm{H}_{6}$ (red), $\mathrm{CH}_{4}$ (yellow), and $\mathrm{CO}$ (green) yields along the length of the catalyst bed as predicted by the model for $20 \mathrm{Cu} / 80 \mathrm{Fe} / \mathrm{K}$ catalyst at $300{ }^{\circ} \mathrm{C}$ and 20 bar total pressure.

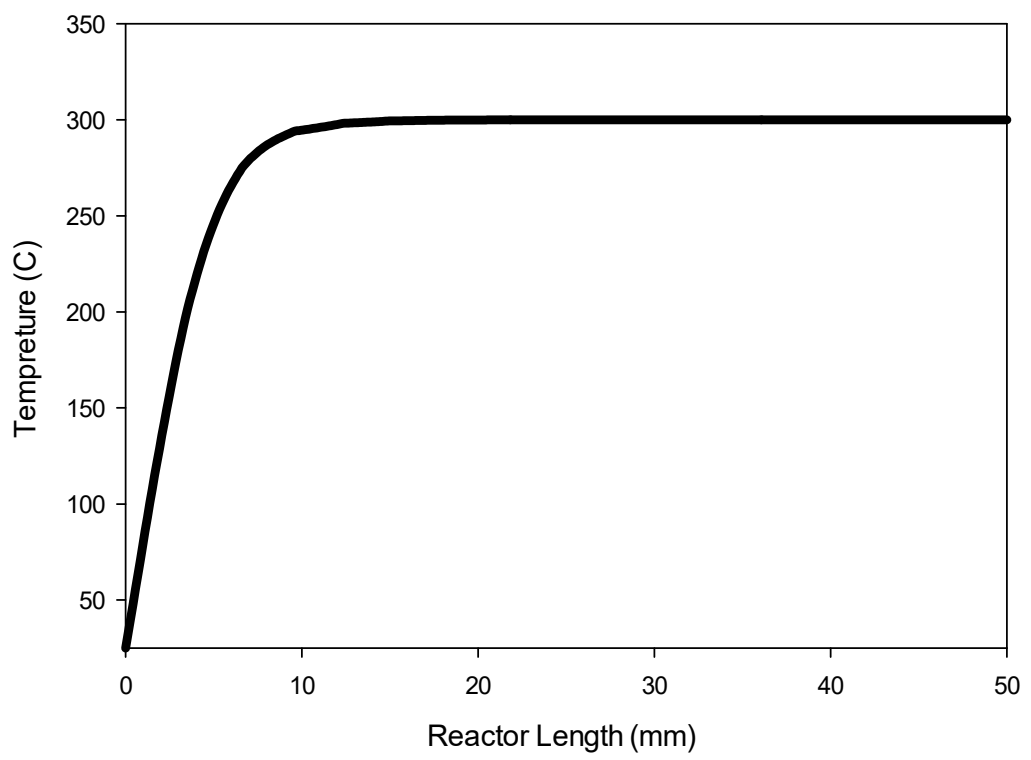

Figure 9. Profiles of temperature $\left({ }^{\circ} \mathrm{C}\right.$ ) along the length (center axis) of the catalyst bed as predicted by the model for $80 \mathrm{Fe} 20 \mathrm{Cu} / \mathrm{K}$ catalyst at 20 bar total pressure and $300{ }^{\circ} \mathrm{C}$ imposed on the reactor wall.

Figure 10 shows the model predictions for conversion and product yields as functions of inverse temperature along with the experimental data. The data at very low temperature, $523.15 \mathrm{~K}$, was found to be too low due to loss of activity of the catalyst. Therefore, the model predictions are fitted with straight lines only for the data at higher temperatures $(573.15 \mathrm{~K}$ and $613.15 \mathrm{~K}$ ) for determining the kinetic parameters for the $80 \mathrm{Fe} 20 \mathrm{Cu} / \mathrm{K}$ catalyst. Figure 8 shows significantly higher conversion and yields than in the case without copper present in the catalyst, indicating a larger pre-exponential factor $\mathrm{kFT}_{0}$ and $\mathrm{kFTs}_{0}$. The kinetic parameters derived by fitting the model predictions (especially $\mathrm{C}_{3} \mathrm{H}_{6}$ and $\mathrm{CH}_{4}$ species) to the experimental data shown in Figure 10 are given in Table 4. The FT reaction activation energy was found to be $72 \mathrm{~kJ} / \mathrm{mol}$, the same as for the catalyst without copper present (Table 6). The rate constants $\mathrm{kFT}_{0}$ and $\mathrm{kFTs}_{0}$ for forming $\mathrm{C}_{3} \mathrm{H}_{6}$ and $\mathrm{CH}_{4}$ are 5 and 1.5 times higher, respectively, than for the catalyst without copper (Table 6). So, the presence of copper has a significant effect on FT. 


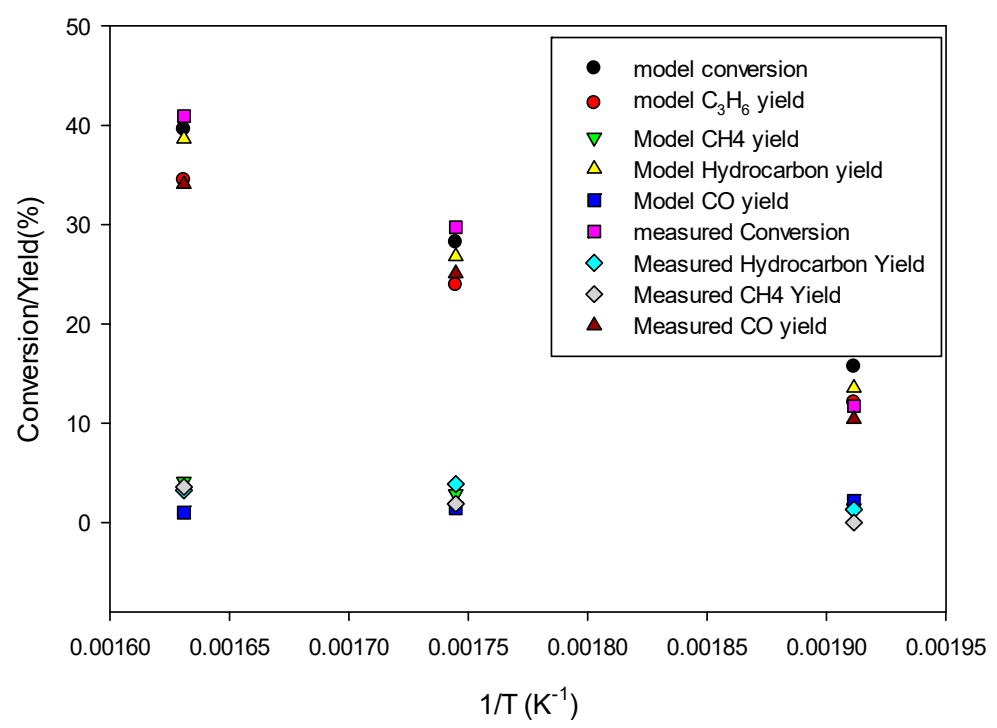

Figure 10. Comparison of model predictions with experimental data as functions of inverse temperature for $80 \mathrm{Fe} 20 \mathrm{Cu} / \mathrm{K}$ catalyst at reactor wall temperatures of $250{ }^{\circ} \mathrm{C}, 300^{\circ} \mathrm{C}$, and $340{ }^{\circ} \mathrm{C}$ and a gas hourly space velocity (GHSV) of $9.59 \times 10^{-4} \mathrm{~L} / \mathrm{g}$ s.

Table 6. Comparison on kinetic parameters of $100 \mathrm{Fe} / \mathrm{K}$ and $80 \mathrm{Fe} 20 \mathrm{Cu} / \mathrm{K}$.

\begin{tabular}{|c|c|c|c|}
\hline Sample & $k_{i, 0}, \mathrm{~mol} /(\mathrm{s} \cdot \mathrm{g} \cdot \mathrm{MPa})(\mathrm{FT})$ & $k_{i, 0}, \mathrm{~mol} /(\mathrm{s} \cdot \mathrm{g} \cdot \mathrm{MPa})\left(\mathrm{CH}_{4}\right)$ & $E_{A, i}, \mathrm{~kJ} / \mathrm{mol}(\mathrm{FT})$ \\
\hline 100Fe/K Ref. [10] & $1.29 \times 10^{3}$ & $5.16 \times 10^{2}$ & 72 \\
\hline $80 \mathrm{Fe} 20 \mathrm{Cu} / \mathrm{K}$ & $6.45 \times 10^{3}$ & $7.74 \times 10^{2}$ & 72 \\
\hline
\end{tabular}

\section{Materials and Methods}

\subsection{Catalyst Synthesis}

For each catalyst, potassium nitrate, iron (III) nitrate nonhydrate, and if necessary copper (II) nitrate trihydrate were dissolved in $50 \mathrm{~mL}$ of boiling deionized water at the desired ratio. The solution was then added to $20 \mathrm{~g}$ of fine gamma alumina powder, stirred with a stir bar to form a paste-like consistency, heated to $90^{\circ} \mathrm{C}$, and allowed to dry. The resulting catalyst material was then calcined overnight at $350{ }^{\circ} \mathrm{C}$ and subsequently cooled back down to room temperature. Upon impregnation and calcification, the catalyst material agglomerates and a mortar and pestle were used to achieve an average surface area of $22 \mathrm{~m}^{2} / \mathrm{g}$. It is worth noting that the surface area of the support calcined without additional metals present has a surface area of $77 \mathrm{~m}^{2} / \mathrm{g}$ and was found not active for $\mathrm{CO}_{2}$ hydrogenation. All catalysts synthesized had a compositional mass ratio of $16 \mathrm{M}: 12 \mathrm{~K}: 100 \mathrm{Al}_{2} \mathrm{O}_{3}$ (unless otherwise specified), where $\mathrm{M}$ includes the total mass of copper and iron components. Different catalyst formulas are denoted by the molar ratio of iron to copper in the catalyst. Potassium and gamma aluminum oxide remain constant throughout all catalysts unless otherwise noted.

\subsection{Catalytic Activity Measurement}

Twenty grams $(20 \mathrm{~g})$ of catalyst was packed into the reactor vessel, a $\frac{1}{2}$ inch outer diameter steel tube 12 inches in length. Roughly 10 inches of the tube were packed with catalyst, and glass wool plugs were used at either end to secure the catalyst within the reactor vessel. $\mathrm{H}_{2}, \mathrm{CO}_{2}$, and $\mathrm{N}_{2}$ gas flow rates were controlled via three separate mass flow controllers, and the overall pressure of the system was held at 290 psi ( 20 bar). The pressure was controlled by a back pressure valve at the end of the system. Temperature was controlled via an aluminum block set around the reactor vessel with four separate heating elements and thermocouples. Water and some liquid oil fractions (C6+) were removed from the gas product stream via a cold trap set at $10{ }^{\circ} \mathrm{C}$. The amount of liquid oil trapped is 
negligible and does not affect the overall selectivity data. The water component was also checked for alcohols and determined to have a concentration of less than $1 \mathrm{mmol}$.

All catalysts were reduced under a pure $\mathrm{H}_{2}$ gas flow $(100 \mathrm{ccm})$ overnight, after which the input was altered to match our desired $\mathrm{CO}_{2}: \mathrm{H}_{2}: \mathrm{N}_{2}$ (25:75:10 unless otherwise specified) ratio without any purge or drop in pressure. The flow rate in all experiments was kept to $110 \mathrm{ccm}$, with a fixed $\mathrm{N}_{2}$ rate of $10 \mathrm{ccm}$ for use as an internal standard. The GHSV was $2.6 \times 10^{-4} \mathrm{~L} / \mathrm{s} \mathrm{g}$ for all tests. The effluent gases were analyzed in real time using an inline gas chromatograph (GC) (Agilent Technologies, Fast RGA analyzer, Santa Clara, CA, USA). Hydrocarbons were separated using an HP-Al/S column (Agilent Technologies, 19091P-512, $25 \mu \mathrm{m} \times 320 \mu \mathrm{m} \times 8 \mu \mathrm{m}$ ) and detected with an FID detector. Fixed gases $\left(\mathrm{H}_{2}, \mathrm{CO}_{2}, \mathrm{CO}, \mathrm{N}_{2}\right)$ were separated on a Unibead IS column $(4 \mathrm{ft}, 60 / 80$ mesh in UltiMetal) and a $5 \AA$ molecular sieve column $(8 \mathrm{ft}, 60 / 80$ mesh) and detected with a TCD detector. It is important to note that all selectivites and yields are reported on a per carbon atom consumed basis and not per mole of product (i.e., propane selectivity is weighted by 3 due to the fact that it accounts for three carbon atoms per molecule).

\subsection{Characterization}

Powder X-ray diffraction analysis was performed on a Rigaku Smartlab X-ray Diffractometer using a $\mathrm{Cu} \_\mathrm{K} \alpha$ source. A Thermo Scientific K-alpha equipped with a monochromatic $\mathrm{Al} \mathrm{K} \alpha$ source and $180^{\circ}$ double focusing hemispherical analyzer with 128-channel detector was used to collect X-ray photoelectron spectroscopy data. SEM measurements were performed with a Carl Zeiss Supra 55 Schottky thermal field emitting microscope using a 30 um aperture at 5-15 KV accelerating voltage. EDS measurements were performed using an Oxford instruments (Abington, UK) $80 \mathrm{~mm}$ silicon drift detector, X-Max 80, inside the Supra 55 SEM using an accelerating voltage of $5 \mathrm{kV}$ and working distance of $8.5 \mathrm{~mm}$. The detector was calibrated with a copper standard. Data acquisition was collected on 2048 channels for 500,000 counts using a process time setting of 4 with pulse pile up correction. The quantitative analysis was performed unnormalized using the supplied $5 \mathrm{kV}$ quantitative standard database.

\section{Conclusions}

The synthesis of useful hydrocarbons from carbon dioxide and hydrogen is a matter of interest for scientific study. In order to combat some of the detrimental effect of water on iron-based $\mathrm{CO}_{2}$ hydrogenation catalysts, copper was added to the catalyst blend. The addition of copper showed a net gain in $\mathrm{CO}_{2}$ hydrogenation activity and decreased the amount of unwanted byproducts significantly. The $90 \mathrm{Fe} 10 \mathrm{Cu} / \mathrm{K}$ catalyst was determined to be the ratio of copper to iron that yielded the best catalytic activity. The copper does not affect the crystallinity or dispersion of the catalyst, but does create some phase separation effects if the amount of copper added is too high. Copper significantly improves the kinetics of FT reactions, as predicted by the model after accounting for the transport limitations imposed by the particles, the porosity of the bed, and of the catalyst particles consistent with experimental data. The data obtained at different temperatures enable us to derive the activation energy for the FT reaction when copper is included. It was found that the diffusive transport is relatively fast compared to the reaction rate in the particles, and support particle porosity has a significant effect on the conversion and yield.

Acknowledgments: This work was supported by the Office of Naval Research both directly and through the Naval Research Laboratory. The research was performed while M.J.B. held an ASEE Research Associateship Award at the Naval Research Laboratory.

Author Contributions: M.J.B. wrote the publication and conducted all catalyst synthesis and characterization not otherwise attributed. R.A. was responsible for modeling catalyst activity. H.W. acted as the primary investigator and supervised the project. J.W.B. performed XPS analysis and contributed laboratory materials. D.H. and F.W.W. were the architects of the "seawater to jet fuel" project and contributed intellectually.

Conflicts of Interest: The authors declare no conflicts of interest. 


\section{References}

1. Lengyel, G.J. Department of Defense Energy Strategy: Teaching an Old Dog New Tricks; 21st Century Defense Initiative Foreign Policy Studies; The Brookings Institution: Washington DC, USA, 2007. Available online: https:/ /www.brookings.edu/wp-content/uploads/2016/06/lengyel20070815.pdf (accessed on 19 September 2017).

2. Petroleum Quality Information System Report (PQIS); Defense Logistics Agency Energy, DLA Energy-QT: Fort Belvoir, VA, USA, 2010.

3. US Navy Energy, Environment \& Climate Change. SECNAV Energy Goals. Available online: http:/ / www.navy.mil/features/Navy_EnergySecurity.pdf (accessed on 17 September 2017).

4. Coffey, T.; Hardy, D.R.; Bresenbruch, G.E.; Schultz, K.R.; Brown, L.C.; Dahlburg, J.P. Hydrogen as a Fuel for DOD; Defense Horizons 36; National Defense University Press: Washington DC, USA, 2003.

5. Eisaman, M.D.; Parajuly, K.; Tuganov, A.; Eldershaw, C.; Chang, N.; Littau, K.A. $\mathrm{CO}_{2}$ extraction from seawater using bipolar membrane electrodialysis. Energy Environ. Sci. 2012, 5, 7346-7352. [CrossRef]

6. Willauer, H.D.; DiMascio, F.; Hardy, D.R.; Williams, F.W. Feasibility of $\mathrm{CO}_{2}$ extraction from seawater and simultaneous hydrogen gas generation using a novel and robust electrolytic cation exchange module based on continuous electrodeionization Technology. Ind. Eng. Chem. Res. 2014, 53, 12192-12200. [CrossRef]

7. Vourrosa, A.; Garagounisa, I.; Kyriakoua, V.; Carabineiroc, S.A.C.; Maldonado-Hódard, F.J.; Marnellosb, G.E.; Konsolakis, M. Carbon dioxide hydrogenation over supported Au nanoparticles: Effect of the support. J. $\mathrm{CO}_{2}$ Util. 2017, 19, 247-256. [CrossRef]

8. Porosoff, M.; Yan, B.; Chen, J.G. Catalytic reduction of $\mathrm{CO}_{2}$ by $\mathrm{H}_{2}$ for synthesis of $\mathrm{CO}$, methanol and hydrocarbons: Challenges and opportunities. Energy Environ. Sci. 2016, 9, 62-73. [CrossRef]

9. Willauer, H.D.; Ananth, R.; Olsen, M.; Drab, D.; Hardy, D.R.; Williams, F.W. Modeling and kinetic analysis of $\mathrm{CO}_{2}$ hydrogenation using a $\mathrm{Mn}$ and K-promoted Fe catalyst in a fixed-bed reactor. J. $\mathrm{CO}_{2}$ Util. 2013, 3, 56-64. [CrossRef]

10. Bradley, M.; Ananth, R.; Willauer, H.; Hardy, D.; Baldwin, J.; DiMascio, F.; Williams, F. The role of catalyst environment on $\mathrm{CO}_{2}$ hydrogenation in a fixed-bed reactor. J. $\mathrm{CO}_{2}$ Util. 2016, 17, 1-9. [CrossRef]

11. Graciani, J.; Mudiyanselage, K.; Xu, F.; Baber, A.E.; Evans, J.; Senanayake, S.D.; Stacchiola, D.J.; Liu, P.; Hrbek, J.; Sanz, J.F.; et al. Highly active copper-ceria and copper-ceria-titania catalysts for methanol synthesis from $\mathrm{CO}_{2}$. Science 2014, 345, 546-550. [CrossRef] [PubMed]

12. Huang, C.-H.; Tan, C.-S. A Review: $\mathrm{CO}_{2}$ Utilization. Aerosol Air Qual. Res. 2014, 14, 480-499. [CrossRef]

13. Wang, W.; Wang, S.; Ma, X.; Gong, J. Recent advances in catalytic hydrogenation of carbon dioxide. Chem. Soc. Rev. 2011, 40, 3703-3727. [CrossRef] [PubMed]

14. Dry, M.E. Fischer-Tropsch synthesis over iron catalysts. Catal. Lett. 1990, 7, 241-251. [CrossRef]

15. Rohde, M.P.; Unruh, D.; Schaub, G. Membrane application in Fischer-Tropsch synthesis reactors-Overview of concepts. Catal. Today 2005, 106, 143-148. [CrossRef]

16. Guettel, R.; Kunz, U.; Turek, T. Reactors for Fischer-Tropsch Synthesis. Chem. Eng. Technol. 2008, 31, 746-754. [CrossRef]

17. Rohde, M.P.; Schaub, G.; Khajavi, S.; Jansen, J.C.; Kapteijn, K. Fischer-Tropsch synthesis with in situ $\mathrm{H}_{2} \mathrm{O}$ removal-Directions of membrane development. Mesoporous Mesoporous Mater. 2008, 115, 123-136. [CrossRef]

18. Bayat, M.; Rahimpour, M.R.J. Simultaneous hydrogen injection and in-situ $\mathrm{H}_{2} \mathrm{O}$ removal in a novel thermally coupled two-membrane reactor concept for Fischer-Tropsch synthesis in GTL technology. Nat. Gas Sci. Eng. 2012, 9, 73-85. [CrossRef]

19. Frost, L.; Elangovan, E.; Hartvigsen, J. Production of synthetic fuels by high-temperature co-electrolysis of carbon dioxide and steam with Fischer-Tropsch synthesis. Can. J. Chem. Eng. 2016, 94, 636-641. [CrossRef]

20. Freemantle, M. Microprocessing on A Large Scale. Chemical E Engineering News, 11 October 2004, Volume 82, pp. 39-43. Available online: http://cen.acs.org/articles/82/i41/MICROPROCESSING-LARGE-SCALE. html?type=paidArticleContent (accessed on 17 September 2017).

21. Nie, X.; Wang, X.; Janik, M.J.; Guo, X.; Song, C. Computational Investigation of Fe-Cu Bimetallic Catalysts for $\mathrm{CO}_{2}$ Hydrogenation. J. Phys. Chem. C 2016, 120, 9364-9373. [CrossRef]

22. Hong, J.S.; Hwang, J.S.; Jun, K.W.; Sur, J.C.; Lee, K.W. Deactivation study on a coprecipitated Fe-Cu-K-Al catalyst in $\mathrm{CO}_{2}$ hydrogenation. Appl. Catal. A 2001, 218, 53-59. [CrossRef] 
23. Ando, H.; Xu, Q.; Fujiwara, M.; Matsumura, Y.; Tanaka, M.; Souma, Y. Hydrocarbon Synthesis from $\mathrm{CO}_{2}$ over Fe-Cu catalysts. Catal. Today 1998, 45, 229-234. [CrossRef]

24. Satthawong, R.; Koizumi, N.; Song, C.; Prasassarakich, P. Light olefin synthesis from $\mathrm{CO}_{2}$ hydrogenation over K-promoted Fe-Co bimetallic catalysts. Catal. Today 2015, 251, 34-40. [CrossRef]

25. Pendyala, V.R.R.; Jacobs, G.; Hamdeh, H.H. Fischer-Tropsch Synthesis: Effect of Activation Gas after Varying Cu Promoter Loading Over K-Promoted Fe-Based Catalyst. Catal. Lett. 2014, 144, 1624-1635. [CrossRef]

26. De Smit, E.; de Groot, F.M.F.; Blume, R.; Hävecker, M.; Knop-Gericke, A.; Weckhuysen, B.M. The role of Cu on the reduction behavior and surface properties of Fe-based Fischer-Tropsch catalysts. Phys. Chem. 2010, 12, 667-680. [CrossRef] [PubMed]

27. Zhu, M.; Wachs, I.E. Iron-Based Catalysts for the High-Temperature Water-Gas Shift (HT-WGS) Reaction: A Review. ACS Catal. 2016, 6, 722-732. [CrossRef]

28. Wielers, A.F.H.; Koebrugge, G.W.; Geus, J.W. On the properties of silica-supported bimetallic Fe-Cu catalysts Part II. Reactivity in the Fischer-Tropsch synthesis. J. Catal. 1990, 2, 375-385. [CrossRef]

29. Zhang, J.; Lu, S.; Su, X.; Fan, S.; Ma, Q.; Zhao, T. Selective formation of light olefins from $\mathrm{CO}_{2}$ hydrogenation over Fe-Zn-K catalysts. J. $\mathrm{CO}_{2}$ Util. 2015, 12, 95-100. [CrossRef]

30. Zamgemej, F.T.; Sahebdelfar, S.; Ravanchi, M.T. Conversion of carbon dioxide to valuable petrochemicals: An approach to clean development mechanism. J. Nat. Gas Chem. 2011, 20, 219-231. [CrossRef]

31. Riedel, T.; Schaub, G.; Jun, K.-W.; Lee, K.-W. Kinetics of $\mathrm{CO}_{2}$ Hydrogenation on a K-Promoted Fe Catalyst. Ind. Eng. Chem. Res. 2001, 40,1355-1363. [CrossRef]

32. Fischer, N.; Henkel, R.; Hettel, B.; Iglesias, M.; Schaub, G.; Claeys, M. Hydrocarbons via $\mathrm{CO}_{2}$ Hydrogenation Over Iron Catalysts: The Effect of Potassium on Structure and Performance. Catal. Lett. 2016, 146, 509-517. [CrossRef]

33. Loiland, J.A.; Wulfers, M.J.; Marinkovic, N.S.; Lobo, R.F. Fe $/ \gamma-\mathrm{Al}_{2} \mathrm{O}_{3}$ and $\mathrm{Fe}-\mathrm{K} / \gamma-\mathrm{Al}_{2} \mathrm{O}_{3}$ as reverse water-gas shift catalysts. Catal. Sci. Technol. 2016, 14, 5267-5279. [CrossRef]

34. Kenfack, F.; Langbein, H. Influence of the Temperature and the Oxygen Partial Pressure on the Phase Formation in the System Cu-Fe-O. Cryst. Res. Technol. 2004, 39, 1070-1079. [CrossRef]

35. Pendyala, V.R.R.; Jacobs, G.; Mohandas, J.; Luo, M.; Hamdeh, H.H.; Ji, Y.; Ribeiro, C.M.; Davis, B.H. Fischer-Tropsch Synthesis: Effect of Water Over Iron-Based Catalysts. Catal. Lett. 2010, 140, 98-105. [CrossRef]

36. Lykasov, A.A.; Katkov, A.E. Spinel Phase Relations in the $\mathrm{Fe}_{3} \mathrm{O}_{4}-\mathrm{CuFe}_{2} \mathrm{O}_{4}$ System. Inorg. Mater. 2003, 39, 223-226. [CrossRef]

Sample Availability: Samples of the compounds and catalysts used in this study are available from the authors.

(C) 2017 by the authors. Licensee MDPI, Basel, Switzerland. This article is an open access article distributed under the terms and conditions of the Creative Commons Attribution (CC BY) license (http:/ / creativecommons.org/licenses/by/4.0/). 